\title{
OOJED
}

ISSN: 2166-2681 Print/ 2690-0408 Online

Volume 9, Issue 2 (2020), pp. 211- 222

(C) Journal of Interdisciplinary Studies in Education

http://ojed.org/jise

\section{Teachers Acceptance of the Use of Smartboard in Riyadh Region, Saudi Arabia}

\author{
Eman Mohammed Alturki \\ Ministry of Education, Saudi Arabia \\ Sulaiman Bin Hashim \\ Mohamad Sahari Nordin \\ International Islamic University, Malaysia
}

\begin{abstract}
This study aimed to validate an extended Unified Theory of Acceptance and Use of Technology (UTAUT) based on the data derived from mathematics teachers of Riyadh Region, Saudi Arabia. Taking into account perceived enjoyment, anxiety, and self-efficacy in using smartboard, the study extended the original UTAUT model. It assessed the effects of these three main factors on the teachers' behavioural intention to use smartboard. The study evaluated computer training-invariant of the causal structure of the hypothesized model. The data were collected from a self-reported questionnaire administered to 150 female mathematics teachers in the Saudi intermediate public schools in Riyadh. The results of structural equation modeling supported the adequacy of the hypothesized interrelationships. Moreover, computer training groups appeared to moderate the structural relationships among the constructs of the extended model.
\end{abstract}

Keywords: smartboard, mathematics, Saudi Arabia, behavior intention 


\section{INTRODUCTION}

Technological advancement has impacted various sectors such as in health, transportation, media, communication and education sectors since its evolution in early 2000. These technologies have enabled a sharp improvement in the way people interact, deliver, travel and cure diseases, among others (Bilbao-Osorio, Dutta, \& Lanvin, 2013). The classroom environment, especially in the pedagogical approach, has seen a major shift with the presence of technological tools as teaching aids that assist teachers to deliver the curriculum so that students become more receptive of the lesson in engaging and interactive ways (Trayek \& Hassan, 2013). Reformation has been implemented to make learning more practical, fun, long-lasting and capable of spreading messages at a faster speed than before the existence of these technologies (Davies, Jindal-Snape, Collier, Digby, Hay, \& Howe, 2013). Technology serves as a tool for teachers to achieve the learning outcomes and objectives of the lessons.

One of the technology-based instructional tools in classrooms nowadays is the interactive whiteboard. This interactive whiteboard comes with many different brands, among others are the SMARTboard, eBeam, Mimio, and Promethean (Khambari, 2014 quoted from SMART Technologies Inc., 2006). Other literature refers to Smartboard as an interactive whiteboard (Dilger, 2015; Spears, 2011) that share features of an interactive whiteboard such as extending and projecting what is being displayed on the computer screen while permitting active interaction on the board.

Since the wake of instructional technology and the evidence of its benefits, ample support has been established for the integration technological use in education, particularly in the classroom. For example, Tosuntas, Karadağ and Orhan (2015) found that performance expectancy and the social and effort expectancy produced positive implication impact on behavioural intention; these factors directly affected the acceptance and use of interactive whiteboard among high school teachers. Such relationships extended the understanding of technology beyond Davis's model of technology acceptance (1989), and it is widely referred to as the Unified Theory of Acceptance and Use of Technology (UTAUT). In the context of technology utilization, UTAUT tool has shown both partial and full invariance, including when assessed based on gender differences (Parameswaran, Kishore, \& Li, 2015).

The UTAUT model comprises of four exogenous constructs including social influence, effort expectancy, performance expectancy, and facilitating constraints. Numerous other studies adopted the UTAUT model to examine and investigate technology adoption, which include an international comparison between Korea and the US on the use of mp3 player and Internet banking (Im, Hong, \& Kang, 2015), predictors of the 
approval and use of open data technologies (Zuiderwijk, Janssen, Dwivedi, 2015), and proposed theoretical framework on combining innovativeness with the acceptance behaviour on technology adoption (Turan, Tunc, \& Zehir, 2015).

\section{LITERATURE REVIEW}

The latest and wide-ranging Technology Acceptance Model (TAM) that has been evolved is int what is now called the Technology Acceptance Model 3 (TAM3) developed by Ventakesh and Bala (Gahtani, 2016). Four anchors proposed in TAM3 included computer anxiety, computer selfefficacy, computer playfulness and perceptions of external control. Two additional characteristics-related adjustments recommended in TAM3 are perceived enjoyment and objective usability which are determinants of perceived ease of use.

\section{Enjoyment}

Perceived enjoyment stems from the use of technology; it is the intrinsic reward that comes as a result of performing tasks using technology. Enjoyment is perceived to increase over time as experience in the use of the technology develops (Gahtani, 2016). In a cpmarative study of the use of the Electronic Health Record portal between the US and Portugal, the UTAUT model found that usually those who have health issues had less enjoyment influences on the behavioural intention to use the technology (Tavares \& Oliveira, 2017). In another study, teachers' usage of multimedia-enhanced content is directly affected by their enjoyment levels (Mtebe, Mbwilo \& Kissaka, 2016); if they find it less enjoyable, then the probability of using it is less.

\section{Self-Efficacy}

According to Teo (2015), self-efficacy is the degree of confidence of one capability to use the computer. Jeong and Kim (2017) state that computer self-efficacy has an undeviating effect on computer technology acceptance. A common theme emerged that affect the intention to use technology includes computer self-efficacy (Ahmad et al., 2010; Teo, 2015). The potential entrepreneurial model to measure self-efficacy of business people is an important and direct determinant with behavioural intention to use technology (Moghavvemi, Mohd Salleh \& Standing, 2016). 


\section{Anxiety}

Computer anxiety was hypothesized to decrease over time as user gain more exposure and experience with the system specifically the hands-on experience (AL Gahtani, 2016). In a study conducted by Hussein (2017), it is described as the level of unfavourable affective or emotional response to the use of technology or any related ideas. The anxiety deficiency in using the system is related to students' effort expectancy of their behavioural intention (BI) for the use of technology (McKeown \& Anderson, 2016).

\section{The Study Hypotheses}

After having considered the theoretical and conceptual foundations of the study, the study used three main constructs (perceived enjoyment, selfEfficacy, and anxiety) as the independent's factors that could influence the dependent variable (Behaviour Intention to use interactive smartboard), and then the following hypotheses were drawn:

H1. The main three exogenous constructs of acceptance and the use of interactive smartboard technology are valid and reliable.

H2. Perceived enjoyment has a direct influence on the teachers' behaviour intention to use interactive smartboard.

H3. Self-Efficacy has a direct influence on the teachers' behaviour intention to use interactive smartboard.

H4. Anxiety has a direct negative influence on the teachers' behaviour intention to use interactive smartboard.

\section{RESEARCH METHOD}

The study sample comprised of 150 female mathematics teachers in Saudi intermediate public schools in Riyadh (the capital city of Saudi Arabia). The sample size was deemed adequate for the application of structural equation modeling (SEM) to address the research hypotheses. For data collection process, the study administered a self-reported questionnaire containing 15 items measuring the main four constructs of the study which are Perceived Enjoyment (3 items), Self-Efficacy (4 items), Anxiety (4 items), and Behavioural Intention to use the interactive smartboard (4 items). These constructs consist of items to which respondents would indicate on a 5-point Likert scale the extent of their agreement or disagreement with each assertion. The 5-points Likert scale ranging from: (i) as "strongly disagree," to (ii) as "strongly agree." The content validity of questionnaire items was developed by experts before being commissioned for this study. The Cronbach's Alpha indices were 
comfortably above the threshold of $\alpha>$.70, hence meeting the requirement of using reliable data.

To achieve the objective of testing the study's hypotheses, the study applied a three-stage structural equation modeling, using the $A M O S$ (version 22) model-fitting program to test the research hypotheses. The study first assessed the validity of the measurement model using the confirmatory factor analysis for the main four constructs. Next, the study examined the good-fit of the full-fledged model. Finally, the study cross-validated the model to explore the likelihood of the moderating effects of computer training of the model. The hypothesized models were estimated using the covariance matrix derived from the data; thus, the estimation procedure satisfied the underlying statistical distribution theory, and yielding estimates of desirable properties.

The study adopted maximum likelihood estimation in generating estimates of the full-fledged model. Once a model was estimated, we applied a set of conventionally accepted criteria to evaluate its goodness of fit. In deciding what constitutes a good fit model, we assessed the, (1) consistency of the hypothesized model with the empirical data, (2) reasonableness of the estimates, and (3) the proportion of variance of the dependent variables accounted for by the exogenous variables. Data analysis further employed fit indexes that include CFI (Comparative Fit Index), RMSEA (Root Mean Square Error of Approximation) and the relative Chi-square ( $\chi 2 / \mathrm{df})$. Hair, Black, Babin, and Anderson, (2013) recommend that value of between 2 and 5 is the measurement acceptable for the normed chi-square (CMIN/df), while a value must be greater than 0.90 , but not reaching $1.0(1>\mathrm{CFI} \geq 0.90)$ for comparative fit index (CFI), A CFI value of less than 0.90 and more than 1.0 shows that the hypothesized models did not fit the data. Lastly, for rational error of estimation of Root Mean Square Error of Approximation (RMSEA), a value of 0.00 implies an exact fit; a value of less than 0.05 indicates a close approximate fit; a value of between 0.05 and 0.08 suggests a reasonable error of approximation (a fair/moderate fit); a value of between 0.08 and 0.10 denotes a mediocre fit; and a RMSEA value of $>0.10$ suggests poor fit. Furthermore, to test the moderation effect of computer training multi-group analyses were done to determine computer training variance of the study's model. A two-step simultaneous analysis on both the teachers with training $\left(\mathrm{n}_{1}=78\right)$ and teachers without training $\left(\mathrm{n}_{2}=72\right)$ was conducted, to establish the variance. This was done through the use of un-constraining the factor loadings, intercepts, and residual errors; the results derived a baseline Chi-square value. Second, all loadings intercepts of the residual errors were constrained to be equal in the two samples. 
Table 1

Measurement of the variables of the hypothesized model

\begin{tabular}{|c|c|c|c|c|c|}
\hline Construct & Code & Item & Mean & SD & Alpha \\
\hline \multirow{4}{*}{$\begin{array}{l}\text { Behaviour } \\
\text { Intention } \\
\text { to use } \\
\text { interactive } \\
\text { smartboard }\end{array}$} & BI1 & $\begin{array}{l}\text { I intend to use an interactive } \\
\text { smartboard in the future. }\end{array}$ & 4.23 & 0.97 & \multirow{4}{*}{0.90} \\
\hline & $\mathrm{BI} 2$ & $\begin{array}{l}\text { I predict to use an interactive } \\
\text { smartboard in the future. }\end{array}$ & 4.25 & 0.87 & \\
\hline & $\mathrm{BI} 3$ & $\begin{array}{l}\text { I plan to use an interactive } \\
\text { smartboard in the future. }\end{array}$ & 4.08 & 1.05 & \\
\hline & BI4 & $\begin{array}{l}\text { I will strongly recommend } \\
\text { others to use interactive } \\
\text { smartboard. }\end{array}$ & 4.07 & 1.02 & \\
\hline \multirow{3}{*}{$\begin{array}{l}\text { Perceived } \\
\text { Enjoyment }\end{array}$} & EN1 & $\begin{array}{l}\text { Using interactive smartboard } \\
\text { is exciting. }\end{array}$ & 3.98 & 0.95 & \multirow{3}{*}{0.89} \\
\hline & EN2 & $\begin{array}{l}\text { Using interactive smartboard } \\
\text { is a good idea. }\end{array}$ & 4.00 & 0.99 & \\
\hline & EN3 & $\begin{array}{l}\text { I have fun while using } \\
\text { interactive smartboard. }\end{array}$ & 3.89 & 1.07 & \\
\hline \multirow{4}{*}{$\begin{array}{l}\text { Self- } \\
\text { Efficacy }\end{array}$} & SE1 & $\begin{array}{l}\text { I could use a smartboard to } \\
\text { teach mathematics if I am } \\
\text { trained on how to use it } \\
\text { before. }\end{array}$ & 4.48 & 0.85 & \multirow{4}{*}{0.80} \\
\hline & SE2 & $\begin{array}{l}\text { I can use a smartboard to teach } \\
\text { mathematics if I saw someone } \\
\text { use it before. }\end{array}$ & 4.27 & 0.92 & \\
\hline & SE3 & $\begin{array}{l}\text { I can use a smartboard to teach } \\
\text { mathematics if I can call } \\
\text { someone for help when I get } \\
\text { stuck. }\end{array}$ & 4.26 & 0.97 & \\
\hline & SE4 & $\begin{array}{l}\text { I can use a smartboard to teach } \\
\text { mathematics if I have just the } \\
\text { built-in help facility for } \\
\text { assistance. }\end{array}$ & 4.28 & 0.86 & \\
\hline \multirow{4}{*}{ Anxiety } & AN1 & $\begin{array}{l}\text { The interactive smartboard } \\
\text { doesn't make me feel } \\
\text { comfortable and relaxed. }\end{array}$ & 2.33 & 1.02 & \multirow{4}{*}{0.87} \\
\hline & AN2 & $\begin{array}{l}\text { I feel apprehensive about } \\
\text { using interactive smartboard. }\end{array}$ & 2.25 & 1.30 & \\
\hline & AN3 & $\begin{array}{l}\text { It scares me to think that I } \\
\text { could lose a lot of information } \\
\text { using interactive smartboard } \\
\text { by hitting the wrong key. }\end{array}$ & 2.71 & 1.35 & \\
\hline & AN4 & $\begin{array}{l}\text { The interactive smartboard is } \\
\text { somewhat intimidating. }\end{array}$ & 2.23 & 1.31 & \\
\hline
\end{tabular}




\section{RESULTS}

Descriptive analysis was first applied to the items that measured the four constructs of interest. Then the internal consistency index, that is the value of Cronbach's alpha for each of these constructs was calculated. The reliability indexes, ranged between .80 and .90 . Table 1 lists the, items, mean scores, standard deviation, and internal consistency indexes of the constructs used in the hypothesized model of the study.

To achieve the objective of testing the first hypothesis of this study, a confirmatory factor analysis (CFA) technique was used first to test each of the hypothesized measurement model. This was to ascertain the constructs were both reliable and valid. The data used to analyze the relationship between both the observed and unobserved latent variables deemed appropriate and yielded good results as per the first hypothesis of this study. Four measurement models were tested. Table 2 indicates the goodness of fit of the measurement models.

Table 2

Results of the fit goodness of measurement models of the study

\begin{tabular}{lccccc}
\hline \multicolumn{1}{c}{ Model } & DF & CMIN & $\chi^{2}$ & CFI & RMSEA \\
\hline Behaviour Intention to use & 2 & 1.48 & 1.48 & 0.99 & 0.057 \\
Perceived Enjoyment & 2 & 0.92 & 0.46 & 1.00 & 0.00 \\
Self-Efficacy & 2 & 2.12 & 1.06 & 0.99 & 0.02 \\
Anxiety & 2 & 0.91 & 0.45 & 1.00 & 0.00 \\
Degree of Freedom $=$ DF; Normed Chi-square $=$ CMIN; Chi-square $=\chi^{2} ;$ Comparative Fit Index $=$ \\
CFI; Root Mean Square Error of Approximation $=$ RMSEA.
\end{tabular}

The chi-square for the four models was ranging in between 0.45 to 1.48 indicating a good fit of the four models with the data. The RMSEA was between the required estimates which were in between .00 to .057 , and the CFI estimates which were in between .99 to 1.00. It therefore means that the findings of the models with its items from data of the study were reliable. Furthermore, the inter-correlation among the indicators did not exceed 0.85, indicating sufficient levels of discriminant validity. Based on the results of CFAs we can conclude that the four models are valid and reliable, and hence further analyses are in order.

The hypothesized structural model of this study was analyzed using the results generated from the measurement model. This model used constructs namely perceived enjoyment, self-efficacy and anxiety as exogenous variables; and behaviour intention to use as an endogenous variable. The results from the analysis of the model yielded consistency of the 
hypothesised causal relationships with the data (relative Chi-square $=$ 94.060; Normed Chi-square $=1.12 ; \mathrm{DF}=84 ; \mathrm{CFI}=.99$; $\mathrm{RMSEA}=.028$ ).

All these fit indices satisfied their critical required parameters; the results, therefore, indicated a fitting of the model with the data. From the results of the study, it can be observed that perceived enjoyment positively influences behaviour intention to use (.59 with a p-values of .001) was statistically significant and practically important which was supported by the data for the second hypothesis of this study, self-efficacy. Self-efficacy positively influences behaviour intention to use (.29 with a P-value of .001 ), was statistically significant and practically important, which was supported by the data for the third hypothesis of this study, anxiety. Anxiety negatively influences behaviour intention to use (-.01 with a P-value of .87). The relationship is negative and statistically not significant and not practical importance hence not being supported by the data for the fourth hypothesis. Figure 1 below summarises the results of structural equation modeling of the hypothesized model.

\section{Figure 1}

The hypothesized structural model with fit indexes

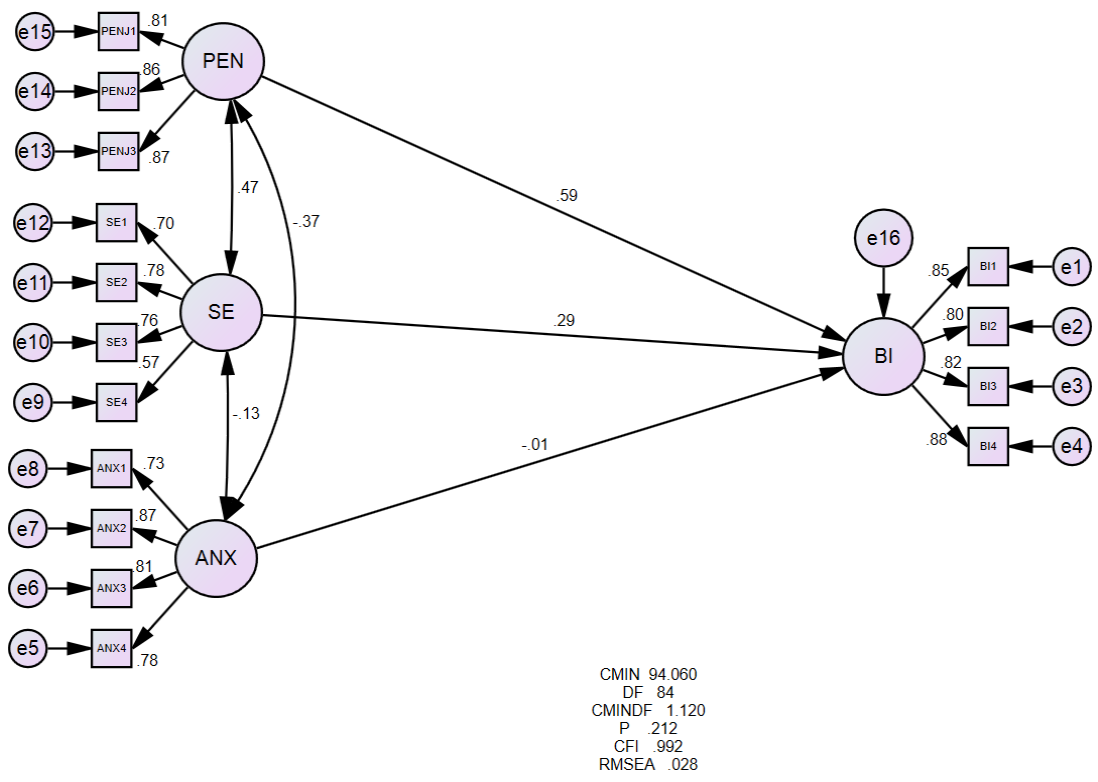

This study was also to test the structural invariance of hypothesized model across computer training groups as the moderator. To test computer 
training-invariant, a simultaneous analysis on both those who received training $(\mathrm{n} 1=78)$ and those did not get any training $(\mathrm{n} 2=72)$ samples was conducted. First, without constraining the structural paths; the results derived a baseline Chi-square value. Next, the structural paths (perceived enjoyment $\rightarrow$ behaviour intention to use; self-efficacy $\rightarrow$ behaviour intention to use; anxiety $\rightarrow$ behaviour intention to use) were constrained to be equal for both groups. The analysis of this constrained hypothesized model produced another Chi-square value, which was then tested against the baseline value for statistically significant differences. The invariance analysis across the trained and non-trained groups resulted in a statistically significant change in the Chi-square value, Chi-square $(\mathrm{df}=3$, alpha $=.005)$ $=9.636$ with a critical value of 12.8 . Simply said, the difference in the Chisquare values between the unrestricted model and the constrained model did not produce a poorer fit model, specifically, the constrained model was not much worse than the unrestricted model. Hence, computer training moderated the causal relationships. The result of the multiple-group structural equation modeling is presented in Table 3.

\section{Table 3}

Results of the multiple group modeling

\begin{tabular}{llcccc}
\hline Variable & \multicolumn{1}{c}{ Mode } & $\chi^{2}$ & DF & $\begin{array}{c}\text { Critical } \\
\text { Value }\end{array}$ & $\begin{array}{c}\text { Result on } \\
\text { moderation }\end{array}$ \\
\hline Computer & Unconstrained & 213.182 & 168 & & \\
Training & Constrained & 222.818 & 171 & 12.84 & Insignificant \\
& Change & 9.636 & 3 & & \\
\hline
\end{tabular}

\section{DISCUSSION AND CONCLUSION}

The findings of the present study have expanded the existing body of knowledge on UTAUT in several ways. First, the results substantiated the psychometric adequacy of the measure of the teachers' acceptance of using a smartboard in their classroom. The measures seemed sufficient to represent the main four constructs in this study which are behaviour intention to use, perceived enjoyment, self-efficacy, and anxiety among female mathematics teachers in Saudi intermediate public schools in Riyadh. The present study provides indications that the extended model did not explain the use of smartboard among those who received training and those did not get any training. The study found that those who did not get any training have more trouble accepting smartboard as a teaching tool in their field. The present study found statistically insignificant effects of computer training as a moderator on the structural relationships between the 
main constructs of the current study. It is very likely that the training was inadequate to make a difference in the interrelationships.

The analysis of the three constructs of the suggested model showed that two of the hypotheses were supported while the other was rejected. Perceived enjoyment and self-efficacy have a significant and practically important relationship with behavioural intention to use, whereas anxiety has no significant relationship with Behavioural Intention to use. The result from the findings of this study is hoped to be able to give ministry of education in Saudi Arabia a clearer understanding of how far teachers accept the new technology which is the Smartboard that been introduced to the teachers at Saudi Arabia. The study concludes that the acceptance factors of the Smartboard among teachers are that the teachers believe that the Smartboard is an enjoyable teaching tool that can increase the teaching performance; they also claimed that they need technical infrastructure, technical team, and support from the administration in the use of the Smartboard in their teaching and learning process. Therefore, perhaps the MOE in Saudi Arabia can organize more training with regards to the use of the Smartboard for the teachers.

This new field of researching in Saudi Arabia, as a developing country, attracts many Scholars to analyze the technology acceptance in the Saudi culture. This study was conducted to find the factors that affect teachers' acceptance of the use of smartboard in their classroom. The study was carried out using Unified Theory of Acceptance and Use of Technology (UTAUT), based on three main factors; perceived enjoyment, self-Efficacy, and anxiety. The study also analyzed the relationship between these factors and teachers' acceptance of the use of smartboard. This study will contribute to:

I. Determining the most influential factors in using smartboard by analyzing three factors that affect teachers' acceptance of the use of smartboard.

II. Enhancing the educational level in Saudi Arabia by inserting new educational methods in the learning process such as smartboard.

III. Encouraging Saudi teachers and students to study the new curriculum of computer technology with the use of a new enhanced model which is smartboard.

This was the first study which utilized and applied the UTAUT in Saudi Arabia to determine and investigate the factors that influence the intermediate mathematics teachers' intention to accept and use interactive smartboards among Saudi teachers. The study added barriers as the independent variable and changing the experience moderator in the original UTAUT model to teaching experience. The study developed and validated the proposed UTAUT in order to support the relationships among the key factors within the Saudi context. Finally, the study validated and confirmed 
the significant role of barriers as a potential factor which influence the behavioural intention to use interactive smartboards in Saudi schools is another theoretical contribution. Furthermore, this study suggested that future research should apply longitudinal approach for data collection in order to investigate the factors that have an influence on the interactive smartboard's adoption.

\section{REFERENCES}

Ahmad, T. B., Madarsha, K. B., Zainuddin, A. M., Ismail, N. A. H., \& Nordin, M. S. (2010). Faculty's acceptance of computer-based technology: Crossvalidation of an extended model. Australasian Journal of Educational Technology, 26(2), 268-279.

Al-Gahtani, S. S. (2016). Empirical investigation of e-learning acceptance and assimilation: A structural equation model. Applied Computing and Informatics, 12(1), 27-50.

Bilbao-Osorio, B., Dutta, S., \& Lanvin, B. (2013). The global information technology report 2013. In World Economic Forum (pp. 1-383).

Davies, D., Jindal-Snape, D., Collier, C., Digby, R., Hay, P., \& Howe, A. (2013). Creative learning environments in education-A systematic literature review. Thinking Skills and Creativity, 8, 80-91.

Dilger, A. (2015). Receptive labeling for common school items for students with autism. Eastern University.

Hussein, Z. (2017). Leading to Intention: The Role of Attitude in Relation to Technology Acceptance Model in E-Learning. Procedia Computer Science, 105, 159-164.

Im, I., Hong, S., \& Kang, M. S. (2011). An international comparison of technology adoption: Testing the UTAUT model. Information \& management, 48(1), 1-8.

Jeong, H. I., \& Kim, Y. (2017). The acceptance of computer technology by teachers in early childhood education. Interactive Learning Environments, 25(4), 496-512.

Khambari, M. N. M. (2014). The impact of interactive whiteboards on teaching and classroom dynamics. The University of Wisconsin-Madison.

McKeown, T. \& Anderson, M. (2016). UTAUT: capturing differences in undergraduate versus postgraduate learning?. Education+Training, 58(9), 945965.

Moghavvemi, S., Saleh, N. A., \& Standing, C. 92016). Entrepreneurs adoption of information system innovation: The impact of individual. perception and exogenous factors on entrepreneur's behavior. Internet Research, 26(5), 11811208.

Mtebe, J. S., Mbwilo, B., \& Kissaka, M. M. (2016). Factors influencing teachers' use of multimedia enhanced content in secondary schools inTanzania. The International Review of Research in Open and Distributed Learning, 17(2).

Parameswaran, S., Kishore, R., \& Li, P. (2015). Within-study measurement invariance of the UTAUT instrument: An assessment with user technology 
engagement variables. Information \& Management, 52(3), 317-336.

Spears, A. Y. (2011). Investigating SMARTBoard technology for mathematics education to improve the learning of digital native students. Doctoral dissertation, Lindenwood University.

Tavares, J., \& Oliveira, T. (2017). Electronic Health Record Portal Adoption: a cross country analysis. BMC medical informatics and decision making, 17(1), 97.

Teo, T. (2015). Comparing pre-service and in-service teachers' acceptance of technology: Assessment of measurement invariance and latent mean differences. Computers \& Education, 83, 22-31.

Tosuntaş, Ş. B., Karadağ, E., \& Orhan, S. (2015). The factors affecting acceptance and use of interactive whiteboard within the scope of FATIH project: A structural equation model based on the Unified Theory of acceptance and use of technology. Computers \& Education, 81, 169-178.

Trayek, F. A., \& Hassan, S. S. S. (2013). Attitude towards the Use of Learning Management System among University Students: A Case Study. Turkish Online Journal of Distance Education, 14(3).

Turan, A., Tunç, A. Ö., \& Zehir, C. (2015). A theoretical model proposal: Personal innovativeness and user involvement as antecedents of unified theory of acceptance and use of technology. Procedia-Social and Behavioral Sciences, 210, 43-51.

Zuiderwijk, A., Janssen, M., \& Dwivedi, Y. K. (2015). Acceptance and use predictors of open data technologies: Drawing upon the unified theory of acceptance and use of technology. Government Information Quarterly, 32(4), 429-440.

EMAN MOHAMMED ALTURKI, Ph.D., is a mathematics teacher, Ministry of Education, Saudi Arabia. His major research interests lie in the area of Instructional Technology in Education. Email: ammoun25@hotmail.com

SULAIMAN BIN HASHIM, Ph.D., is a Senior Lecturer in the Curriculum and Instruction Department, Kulliyyah of Education, International Islamic University Malaysia. His major research interests lie in the area of Instructional Technology, e-Learning, and ICT in Education. Email: sulaimanh@,iium.edu.my

MOHAMAD SAHARI NORDIN, Ph.D., is a professor of education at the International Islamic University Malaysia. His research interest includes assessment, statistical modeling, and teacher education. Email: msahari@iium.edu.my 